\title{
Confinement of $i$ PP chains in the interior of SBA-15 mesostructure ascertained by gas transport properties in iPP-SBA-15 nanocomposites prepared by extrusion
}

Rosa Barranco-García1,2, Juan M. López-Majada¹, Vicente Lorenzo³, José M. Gómez-Elvira¹, Ernesto Pérez $^{1}$, María L. Cerrada ${ }^{*}$

1Instituto de Ciencia y Tecnología de Polímeros (ICTP-CSIC), Juan de la Cierva 3, 28006 Madrid, Spain.

2PhD Program in Industrial Technology: Chemical, Environmental, Energetic, Electronic, Mechanical and Materials at Universidad Rey Juan Carlos, Madrid 28933, Spain.

3Grupo de Investigación "POLímeros: Caracterización y Aplicaciones" (U. A. del ICTP-CSIC), E.T.S.I. Industriales, Universidad Politécnica de Madrid, José Gutiérrez Abascal 2, 28006 Madrid, Spain

Correspondence to: mlcerrada@ictp.csic.es

\section{Abstract}

Different nanocomposites based on isotactic polypropylene (iPP) and mesoporous SBA-15 silica have been prepared by melt extrusion as an attempt of incorporating iPP within the nanometric SBA-15 pores by the action of shear forces during processing. The observed inclusion of IPP chains in the SBA-15 leads to a change in the gas transport properties of the resultant iPP/SBA-15 membranes together with the improvement of their ultimate mechanical performance. Existence of confinement effects is observed, consequently, by the exhibited transport properties and is confirmed through realtime variable-temperature Small Angle X-ray Scattering (SAXS) experiments with synchrotron radiation. The former indicates that the mesostructure of silica is full, i.e., these particles essentially act as fillers. The latest has been proved by the presence of a discontinuity in the intensity of the (100) SBA-15 diffraction, which turn SAXS measurements at variable temperature into a valuable means to corroborate the development of IPP crystallites within SBA-15 channels. Moreover, SAXS profiles provide information about the most probable long spacing of chains located outside the SBA-15 nanospaces. On the other hand, changes in the $\beta$ viscoelastic relaxation have been correlated to the influence of SBA-15 in the IPP amorphous regions. All the structural features have been crucial for the understanding the mechanical response shown by these nanocomposites. Mesoporous particles exert a reinforcing role and reduce the deformation capacity in the ultimate materials as their content is increased.

Keywords: iPP/SBA-15 nanocomposites; permeability; diffusion coefficient; synchrotron SAXS measurements; reinforcement. 


\section{Introduction}

Isotactic polypropylene (iPP) finds many applications in several fields such as packaging, films, textiles, automotive, technical parts and consumer products. Some key property requirements in these fields are good transparency, mechanical response, thermal characteristics as well as barrier properties. To achieve such properties, its blending or combination with other polymers, particles or nanoparticles has been a common top-down approach over many decades. The resultant iPP based materials have exhibited improved properties compared with those shown as individual component and, sometimes, that enlarged response involves additional and very useful features or functionalities: improved toughness [1]; faster crystallization [2]; biocidal activity [3,4]; superior gas barrier behavior [5,6]; changes in mechanical response [7]; electromagnetic shielding characteristics [8,9]; enhancement in water vapor permeability $[6,10]$.

Mesoporous silicas become, between the ordered porous materials, one of the most versatile classes since their discovery in 1992, when parallel one-dimensional pores of about $3 \mathrm{~nm}$ in diameter and disposed in hexagonal arrangements were synthesized by Exxon Mobil [11]. That first mesoporous silica was named as Mobil Crystalline Materials No. 41 or MCM-41. In 1998, other mesoporous structures were manufactured at the University of California, Santa Barbara. The SBA-15 is the best known member from this family and it displayed also a hexagonal arrangement [12] similar to that found in MCM-41, with pore diameters ranging from 5 to $10 \mathrm{~nm}$. These ordered porous silicas on the nanoscale have found important applications in different areas, among others: catalysis, optics, coatings, cosmetics, gas-separation, bio-separation, drug delivery, diagnostics, and nanotechnology. Presence of these mesostructures, constituted by ordered long channels, becomes a very interesting feature for using these particles as a minority component in polymeric based materials. They can act either as confinement spaces or as pores if polymer is or not able, respectively, to fully fill their nanometric channels. The whole properties spectrum can be, accordingly, altered. A precise and easy knowledge of the existence of confined macrochains is, then, required. Existence of small crystallites within mesoporous channels has been reported by means of Differential Scanning Calorimetry (DSC) for nanocomposites attained by in situ polymerization through the appearance of a small melting process at temperatures lower than the primary melting event. Those materials were based on high density polyethylene (HDPE) with either pristine or decorated MCM-41 particles, as well as on ultra high molecular weight polyethylene (UHMWPE) and neat SBA-15 silica [13-15].

Some investigations concerning nanocomposites prepared by in situ polymerization [16] of poly(N-isopropylacrylamide)/SBA-15 and composites based on polyethylenimine (PEI) with MCM-41 or SBA-15 by the wet impregnation method of PEl into mesoporous silica $[17,18]$ referred the Small Angle 
X-ray Scattering, SAXS, at room temperature as useful technique for learning on the presence of those polymers within the silica mesostructure.

Evaluation of gas transport properties in these polymer-mesoporous silica composites can also constitute an important means to learn if polymer is confined within the channels or, on the contrary, if available pores have been left unfilled and porous materials have been developed. Two completely different scenarios can be then achieved. The former will imply the reduction of transport properties in the resultant membranes, like permeability and diffusion coefficients, which is largely attractive for some applications in the case of iPP based composites, like packaging and films, while the latest comprises the basis of the as-called mixed matrix membranes (MMMs), involving an increase in those coefficients and other interesting applicability aspects.

The present work aims the obtainment of (nano)composites based on isotactic polypropylene and different contents in mesoporous SBA-15 particles by a cost-effective and an environmentallyfriendly method, without involving the use of any solvent. Thus, melt extrusion has been chosen for its common industrial implementation. Transport properties of membranes will be evaluated to find out, together with real-time variable-temperature SAXS experiments, if there is existence or absence of eventual confinement effects in the ultimate materials. The results attained by these two approaches will be, then, compared with those derived from the phase transitions observed by Differential Scanning Calorimetry (DSC). Moreover, the influence of SBA-15 on the iPP crystalline details will be determined by Wide Angle X-ray Diffraction (WAXD) as well as from the most probable long spacing assessed by SAXS. Characteristics of the amorphous regions will be analyzed by dynamic mechanical analysis (DMA). Finally, the ultimate mechanical performance will be examined by stress-strain tests and indentation experiments.

\section{Experimental part}

\subsection{Materials and chemicals}

A commercially available metallocene-catalyzed isotactic polypropylene (Metocene HM562P: melt flow index of $15 \mathrm{~g} / 10 \mathrm{~min}$, ISO 1133, kindly supplied by LyondellBasell) has been used in the present research as polymeric matrix. The SBA-15 particles were purchased from Sigma-Aldrich (specific surface area, $S_{B E T}=517 \mathrm{~m}^{2} / \mathrm{g}$; total pore volume, $V_{t}=0.83 \mathrm{~cm}^{3} / \mathrm{g}$; average mesopore diameter, $\left.D_{p}=6.25 \mathrm{~nm}[19]\right)$ and were used as received.

\section{2. (Nano)composite and film preparation}

Composites with different contents in SBA-15 particles $(1,4,8$ and $13 \%$ in weight, labeled as iPP-SBA1, IPP-SBA4, iPP-SBA8 and iPP-SBA13 respectively) were processed by melt extrusion in a 
corotating twin-screw microextruder (Rondol) at a rate of $60 \mathrm{rpm}$. Both polymer and SBA-15 were dried previously for $24 \mathrm{~h}$ under vacuum at $110^{\circ} \mathrm{C}$. A screw temperature profile of $115,170,180,185$ and 190 ${ }^{\circ} \mathrm{C}$ was used from the hopper to the die, being the length-to-diameter ratio $20: 1$. Then, films were obtained by compression molding at $190{ }^{\circ} \mathrm{C}$ and at 30 bar for 6 minutes in a hot-plate Collin press. $\mathrm{A}$ relatively fast cooling process at a rate of around $80^{\circ} \mathrm{C} / \mathrm{min}$ was applied to the different films from their melt to room temperature between plates under pressure (30 bar). This thermal treatment is similar to those applied at industrial scale.

\subsection{Scanning electron microscopy}

Experiments of high resolution field emission scanning electron microscopy (FESEM) were carried out in a S-8000 Hitachi equipment at room temperature in different cryo-fractured sections of composites at distinct mesoporous content. Those thin sections of around $40 \mathrm{~nm}$ were cut by cryoultramicrotomy (Leica EM UC6) at $-120^{\circ} \mathrm{C}$ and deposited in a holder.

\subsection{Thermogravimetric analysis}

Thermogravimetric analysis (TGA) was performed in a Q500 equipment of TA Instruments under air or nitrogen atmosphere at a heating rate of $10^{\circ} \mathrm{C} / \mathrm{min}$. An accurate determination of the SBA15 amount in the nanocomposites prepared by extrusion has been carried out as an average of the values obtained under the two atmospheres. The resulting values of the SBA-15 content are listed in Table 1.

\subsection{Gas Transport Behavior}

Permeability measurements were performed by using a non-commercial experimental device that was developed in our laboratory. This device consists of a permeation cell with two chambers that are separated by the membrane, a thermostatic bath and a system for measuring pressure. The permeation cell is a stainless steel $47 \mathrm{~mm}$ filter holder (Millipore XX4404700) (effective area $=13.8$ $\mathrm{cm}^{2}$ ). Automated data collection was performed by absolute pressure sensors (MKS Baratron) and temperature sensors. Gas permeability of the specimens has been determined by means of diffusion experiments through an initially purged membrane. High vacuum $\left(\sim 10^{-4}\right.$ mbar $)$ was applied in both the high-pressure and low-pressure chambers separated by the film. After purging the system, a step variation of the pressure has been imposed on the high pressure side of the membrane $\left(p_{H}=p_{0}\right.$ for time, $t>0$ ) and the pressure on the low pressure side, $p_{L}$, has been monitored. Before each experiment, the leak curve was determined by measuring the variation of the pressure with time in the low-pressure chamber in vacuum, and all membranes were degassed under vacuum overnight between runs. The experiments were carried out with nitrogen $\left(\mathrm{N}_{2}\right)$, oxygen $\left(\mathrm{O}_{2}\right)$, and carbon dioxide $\left(\mathrm{CO}_{2}\right)$ at $\mathrm{p}_{\mathrm{H}} \approx 0.2 \mathrm{MPa}$ 
and at several temperatures ranging from 30 to $60^{\circ} \mathrm{C}$. Three membranes were tested for each gas at each temperature and the average values are reported. Reproducibility of the measurement method is quite good and the experimental results show that standard deviation of the transport parameters is less than $5 \%$ of the average value.

\subsection{Differential Scanning Calorimetry}

Calorimetric analyses were carried out in a TA Instruments Q100 calorimeter connected to a cooling system and calibrated with different standards. The sample weights were around $3 \mathrm{mg} . \mathrm{A}$ temperature interval from -40 to $180{ }^{\circ} \mathrm{C}$ was studied at a heating rate of $20{ }^{\circ} \mathrm{C} / \mathrm{min}$. For the determination of the crystallinity, a value of $160 \mathrm{~J} / \mathrm{g}$ was used as the enthalpy of fusion of a perfectly crystalline material [20-22].

\subsection{X-ray experiments with synchrotron radiation}

Real-time variable-temperature simultaneous SAXS/WAXD experiments were carried out with synchrotron radiation in beamline BL11-NCD at ALBA (Cerdanyola del Valles, Barcelona, Spain) at a fixed wavelength of $0.1 \mathrm{~nm}$. An ADSC detector has been used for SAXS (off beam, at a distance of 294 $\mathrm{cm}$ from sample) and a Rayonix one for WAXD (at about $19 \mathrm{~cm}$ from sample, and a tilt angle of around 30 degrees). A Linkam Unit, connected to a cooling system of liquid nitrogen, was employed for the temperature control. The calibration of spacings was obtained by means of silver behenate and $\mathrm{Cr}_{2} \mathrm{O}_{3}$ standards. The initial 2D X-ray images were converted into 1D diffractograms, as function of the inverse scattering vector, $s=1 / d=2 \sin \theta / \lambda$. Film samples of around $5 \times 5 \times 0.1 \mathrm{~mm}$ were used in the synchrotron analysis.

\subsection{Dynamic mechanical thermal analysis (DMTA)}

Viscoelastic relaxations were measured with a TA Q800 Dynamic Mechanical Thermal Analyzer, working in a tensile mode. The storage modulus, $E$, loss modulus, $E^{\prime \prime}$, and the loss tangent, $\tan \delta$, of the different composites were determined as function of temperature over the range from -150 to $125^{\circ} \mathrm{C}$ at fixed frequencies of $1,3,10$ and $30 \mathrm{~Hz}$, and at a heating rate of $1.5^{\circ} \mathrm{C} / \mathrm{min}$. For this analysis, strips of $2.2 \mathrm{~mm}$ wide and $15 \mathrm{~mm}$ length were cut from the molded films.

\subsection{Mechanical Behavior}

\subsubsection{Stress-strain tests}

Nominal stress-strain tests were performed at a temperature of $25{ }^{\circ} \mathrm{C}$ and a stretching rate of $10 \mathrm{~mm} / \mathrm{min}$ in MTS Q-Test Elite dynamometer with a load-cell of $100 \mathrm{~N}$. Specimens for these experiments were punched out from the polymer films. The dimensions of these strips were $15 \mathrm{~mm}$ 
long, $1.9 \mathrm{~mm}$ wide and around $0.10 \mathrm{~mm}$ thick. At least, six different strips were stretched until fracture at a given specimen.

\subsubsection{Depth sensing indentation measurements}

Depth sensing indentation (DSI) experiments were performed at $20^{\circ} \mathrm{C}$ with a Shimadzu tester (model DUH211S) equipped with a Berkovich-type diamond indenter. At least 10 distinct indentations were carried out at different regions on the surface for the different materials analyzed, iPP homopolymer and its nanocomposites with SBA-15 particles. The experimental protocol consisted in several stages: a) application of a load of $10 \mathrm{mN}$ at a loading speed of $1.46 \mathrm{mN} / \mathrm{s}$; b) maintenance of this constant load for $5 \mathrm{~s}$; and $\mathrm{c}$ ) release of the load at an unloading speed equal than the one used along the loading stage. Finally, indentation depth was registered for 5 additional seconds after reaching the minimum load $(0.02 \mathrm{mN})$.

\section{Results and discussion}

\subsection{Morphological characterization}

Figure 1 shows FESEM micrographs of different composites based on iPP and SBA-15 silica used for this investigation. A rather uniform dispersion of SBA-15 particles is clearly noticeable and an absence of agglomerates with large size is observed, taken into account that these particles commonly possess an average size [15] of $350 \mathrm{~nm}$ wide and $0.9 \mu \mathrm{m}$ long. An evident increase in the number of SBA-15 particles is noticed as its content is raised in the final composite (see precise compositions in Table 1).

Table 1. Average SBA-15 wt.\% content estimated by TGA, crystallinity values determined by WAXD and DSC as well as long spacing obtained from SAXS.

\begin{tabular}{ccccc}
\hline sample & SBA-15 wt.\% by TGA & $f_{c}$ WAXD & $L_{\text {SAXS }}(\mathrm{nm})$ & $f_{c}$ DSC \\
\hline iPP & 0 & 0.60 & 10.8 & 0.60 \\
iPP-SBA1 & 1.4 & 0.60 & 11.0 & 0.59 \\
iPP-SBA4 & 3.9 & 0.59 & 10.9 & 0.61 \\
iPP-SBA8 & 8.0 & 0.59 & 11.1 & 0.58 \\
iPP-SBA13 & 12.8 & 0.58 & 11.3 & 0.61 \\
\hline
\end{tabular}




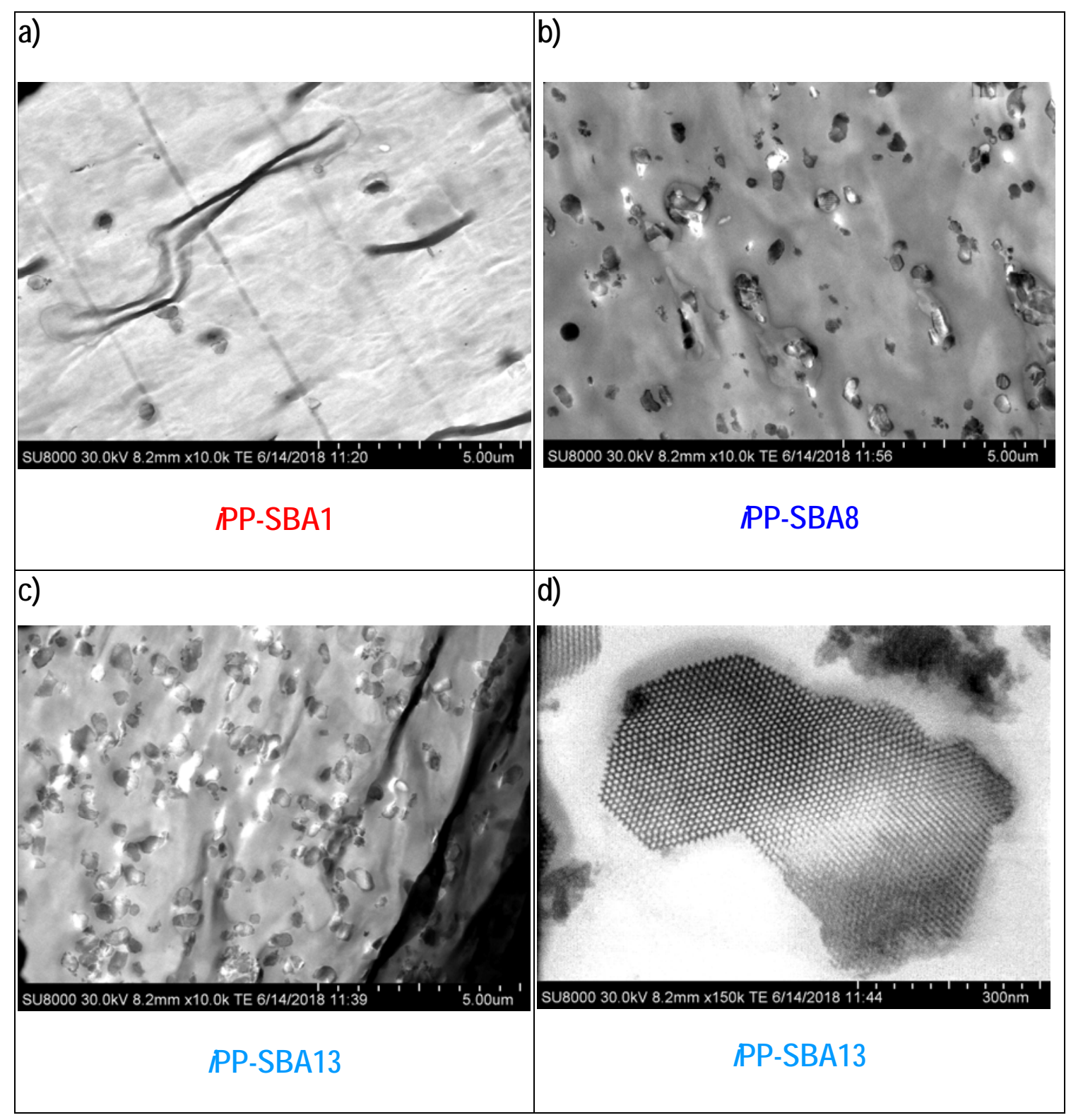

Figure 1. FESEM micrographs for different composites: a) IPPSBA1; b) iPPSBA8, and, c) iPPSBA13 at a scale bar of $5 \mu \mathrm{m}$. d) An individual SBA-15 particle from IPPSBA13 at larger augments (scale bar of $300 \mathrm{~nm})$.

The well-defined channel structure with hexagonal arrangement exhibited by these SBA-15 particles embedded in the composites is undoubtedly shown in Figure 1d for the iPP-SBA13, although this ordering is also seen in the rest of the materials. This feature indicates that regularity at the mesoscale is not affected by the shear forces applied during the preparation approach by extrusion and, accordingly, the hexagonal arrangement of the SBA-15 channels has been maintained. 
These micrographs are not analogous to those found in the powders from the reactor of polyethylene based materials attained from the ethylene polymerization [23] using a titanocene as catalyst, which was supported by a fibrous mesoporous silica in conjunction with methylaluminoxane (MAO) as a cocatalyst. Those materials showed the formation of crystalline polyethylene fibers that consisted predominantly of extended-chain crystals. Variables of the polymerization reactions, like temperature and time, as well as the mesoporous silica used played an important role in the final morphology $[23,24]$ exhibited by those polyethylene powders. These distinct morphological characteristics can be mainly ascribed to the different strategy used for preparation of the resulting materials, the in situ polymerization versus the melt extrusion here used, and to the fact that those polyethylene fibers were directed observed in powders from the reactor, i.e., no further processing technique (compression molding, injection or other one) was applied.

\subsection{Transport Properties}

In polymeric materials, the permeation process can be described by means of the solutiondiffusion model and the Fick's laws [25]. If the concentration of the permeant is low enough, the material parameters that appear in the equations can be assumed to be concentration-independent. Consequently, the temporal variation of the pressure on the downstream side during a pressure step experiment becomes [26]:

$$
p_{L}=\frac{A P p_{0}}{V e}\left(t-\frac{e^{2}}{6 D}+\frac{2 e^{2}}{\pi^{2} D} \sum_{n=1}^{\infty} \frac{(-1)^{n+1}}{n^{2}} \exp \left(-\frac{D n^{2} \pi^{2} t}{e^{2}}\right)\right)
$$

where $e$ is the thickness of the membrane, $V$ is the volume of the low pressure chamber, $A$ the effective film area, $D$ reads for the diffusion coefficient and $P$ is the permeability. The $P_{L}$ and $P_{0}$ are pressures on the low pressure side and on the high pressure side $\left(P_{H}=P_{0}\right.$ for time, $\left.t>0\right)$, respectively, as indicated in the Experimental Section.

Those two material parameters are related by means of:

$$
P=S \cdot D
$$

being $S$ the solubility coefficient.

Figure 2 shows that the asymptotic behavior of $P_{L}$ is linear as deduced from measurements performed under different gases and at distinct temperatures, for the IPP, IPP-SBA8 and iPP-SBA13 samples. This asymptotic limit it is given by:

$$
\lim _{t \rightarrow \infty} p_{L}=\frac{A P p_{0} t_{\text {lag }}}{V e}\left(\frac{t}{t_{\text {lag }}}-1\right)
$$


being the time lag, $t_{\text {lag }}=e^{2} / 6 D$. Therefore, the time lag and, consequently, $D$ can be determined from the intercept of steady-state measurements, $p(t)$ on the time axis.

Figure 2 seems to show different trends depending on the tested gas. The $\mathrm{N}_{2}$ and $\mathrm{O}_{2}$ transport behavior appears rather similar for the iPP homopolymer together with iPP-SBA4 (not represented in Figure 2) and iPP-SBA8 and some small variations are observed in the composite IPP-SBA13, which is the one with the highest mesoporous content. Situation changes for $\mathrm{CO}_{2}$ and a much higher difference with the SBA-15 content for the diffusion coefficients, which are reported in Table 2, is exhibited. This variation on composition is less pronounced in permeability (values listed in Table 3).
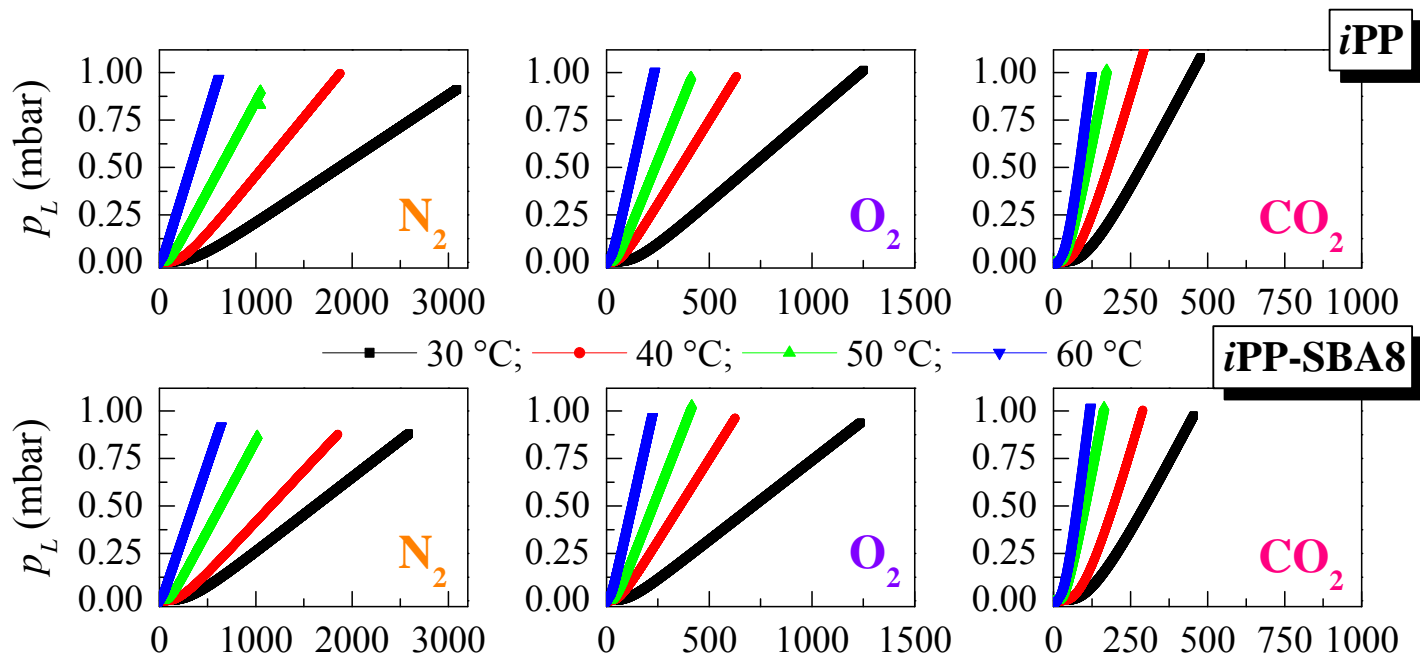

$\longrightarrow 30^{\circ} \mathrm{C} ; \longrightarrow 40^{\circ} \mathrm{C}$

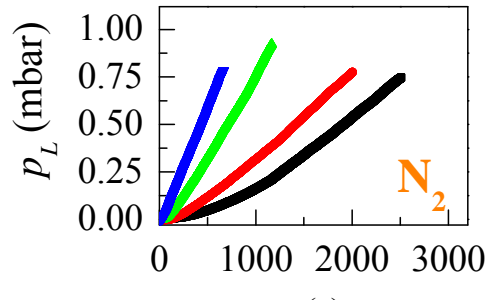

$\mathrm{t}(\mathrm{s})$
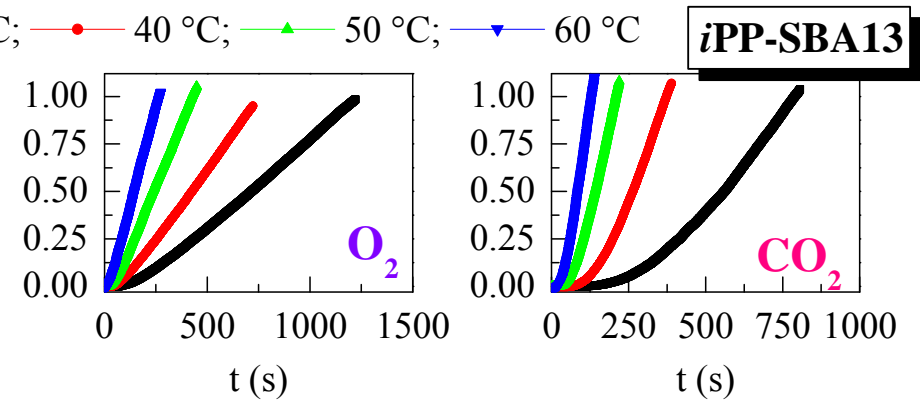

Figure 2. Dependence on time of the pressure measured on the low pressure side, $p_{L}$, at distinct temperatures for different gases $\left(\mathrm{N}_{2}, \mathrm{O}_{2}\right.$ and $\left.\mathrm{CO}_{2}\right)$ through the membranes of $\mathrm{PP}$, IPP-SBA8 and iPPSBA13.

Figure 3 shows the variation with temperature of the diffusion coefficients found in IPP-SBA13 at the distinct gases: a) for $\mathrm{N}_{2} ;$ b) for $\mathrm{O}_{2}$; and c) for $\mathrm{CO}_{2}$. An increase of the $D$ values is observed for the three gases as temperature is raised, as expected. This feature is also found for the other membranes (see values in Table 2). Moreover, it is also remarkable that IPP usually exhibits $D$ values higher than 
those found in the composites. As aforementioned, the largest dependences on SBA-15 content are found for the $\mathrm{CO}_{2}$ transport behavior.
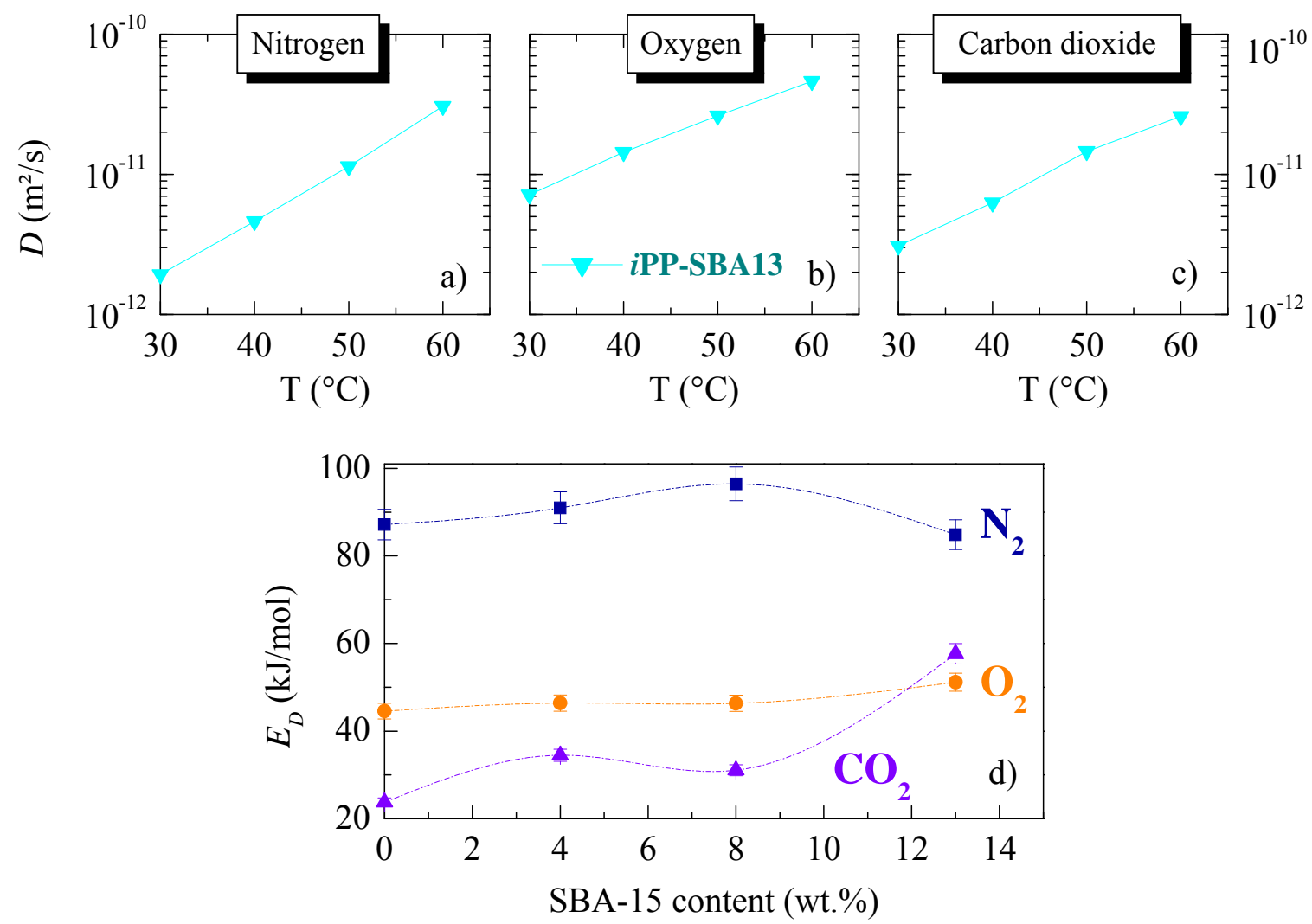

Figure 3. Upper plots: variation on temperature of diffusion coefficients, $D$, for different gases: a) nitrogen; b) oxygen; and, c) carbon dioxide) for the IPP-SBA13 composite. Lower plot: dependence of the activation energy for the diffusion, $E_{D}$, of the different gases for the iPP based materials (homopolymer and composites) at $30^{\circ} \mathrm{C}$. Lines are just a guide to the eye (plot d).

The diffusion coefficient is related to the speed of permeation process to reach steady-state conditions and depends on the size of permeant and on the structure and mobility of the matrix through which diffusion takes place [27]. Michaels and Parker [28] expressed the diffusion coefficient of a semicrystalline polyolefin by

$$
D=D^{*} / \tau \beta
$$

where $D *$ is the diffusion coefficient for the completely amorphous polymer. The parameter $\tau$ reflects the tortuosity of the path caused by the presence of crystalline entities, whereas $\beta$ is mainly related to the lack of mobility in the amorphous regions close to the anchoring points in the crystals [29]. 
Table 2. Diffusion coefficient values $\left(10^{-12} \mathrm{~m}^{2} / \mathrm{s}\right)$ found in iPP and in some composites membranes for the different gases tested.

\begin{tabular}{|c|c|c|c|c|c|}
\hline \multirow{2}{*}{ permeant } & \multirow{2}{*}{$\mathrm{T}\left({ }^{\circ} \mathrm{C}\right)$} & \multicolumn{4}{|c|}{ sample } \\
\hline & & iPP & iPP-SBA4 & iPP-SBA8 & iPP-SBA13 \\
\hline \multirow{4}{*}{$\mathrm{N}_{2}$} & 30 & 3.9 & 3.7 & 3.6 & 1.9 \\
\hline & 40 & 6.1 & 5.4 & 5.2 & 4.6 \\
\hline & 50 & 16.1 & 13.1 & 12.6 & 11.4 \\
\hline & 60 & 43.7 & 40.9 & 40.8 & 30.7 \\
\hline \multirow{4}{*}{$\mathrm{O}_{2}$} & 30 & 8.9 & 8.6 & 10.1 & 7.2 \\
\hline & 40 & 18.7 & 18.5 & 17.7 & 14.4 \\
\hline & 50 & 32.0 & 30.6 & 28.4 & 26.2 \\
\hline & 60 & 50.7 & 51.1 & 50.3 & 46.3 \\
\hline \multirow{4}{*}{$\mathrm{CO}_{2}$} & 30 & 11.3 & 9.1 & 8.7 & 3.1 \\
\hline & 40 & 15.5 & 10.8 & 10.5 & 6.3 \\
\hline & 50 & 30.2 & 29.1 & 28.6 & 14.6 \\
\hline & 60 & 30.9 & 27.6 & 26.9 & 26.0 \\
\hline
\end{tabular}

At first approximation in the composite membranes under study, tortuosity is not only triggered by presence of crystallites but also by incorporation of rigid SBA-15 particles with an average length [15] of $900 \mathrm{~nm}$. This latest contributes to an increase of diffusion hindrance in the composite material [30]. Thus, neat iPP usually exhibits the highest $D_{\mathrm{N} 2}, D_{02}$ and $D_{\mathrm{CO} 2}$ at all temperatures. On the opposite side, the iPP-SBA13 is found. Accordingly, a balance between the characteristics of either iPP crystalline regions (degree of crystallinity and size of crystallites, reported in Table 1 and further discussed) or iPP chains in an amorphous state (also commented below) will rule out the final response, together with presence or absence of the mesoporous particles as well as their content. An aspect that might also exert a significant effect is related to the fact that the long channel nanospaces can be filled with iPP chains or, on the contrary, can remain fully or partially empty.

The diffusive process through isotropic barriers is a thermally activated process, which obeys the Arrhenius expression:

$$
D=D_{0} \exp \left(-E_{D} / \mathrm{RT}\right)
$$

where $E_{\mathrm{D}}$ is the activation energy of the diffusion and $D_{0}$ is a constant that is characteristic of the membrane-permeant system. The $E_{D}$ values obtained for the different testing gases, which were 
calculated from the data in Table 2, are represented in Figure 3d for these samples. It is observed that the composite membranes usually exhibit activation energy values higher than those found in the pristine IPP for the diffusivity process independently of the gas. Even more, it can be seen that activation energy for the diffusion of $\mathrm{CO}_{2}$ is an increasing function of the SBA-15 content. This result points to the fact that mesoporous silica not only increases tortuosity but also decreases the mobility of the macromolecular chains, as will be discussed from DMTA results below.

Table 3. Permeability values (Barrer) found in iPP and in some composites membranes for the different gases tested.

\begin{tabular}{cccccc}
\hline \multirow{2}{*}{ permeant } & $\mathrm{T}\left({ }^{\circ} \mathrm{C}\right)$ & \multicolumn{4}{c}{ sample } \\
\cline { 3 - 6 } & & iPP & iPP-SBA4 & iPP-SBA8 & iPP-SBA13 \\
\hline \multirow{4}{*}{$\mathrm{N}_{2}$} & $\mathbf{3 0}$ & 0.5 & 0.5 & 0.4 & 0.4 \\
& $\mathbf{4 0}$ & 0.8 & 0.7 & 0.6 & 0.5 \\
& $\mathbf{5 0}$ & 1.1 & 1.0 & 1.0 & 1.0 \\
& $\mathbf{6 0}$ & 1.9 & 1.6 & 1.6 & 1.4 \\
\hline \multirow{6}{*}{$\mathbf{O}_{2}$} & $\mathbf{3 0}$ & 1.2 & 1.2 & 1.0 & 1.1 \\
& $\mathbf{4 0}$ & 2.2 & 2.0 & 2.0 & 1.7 \\
& $\mathbf{5 0}$ & 3.2 & 3.2 & 3.0 & 3.0 \\
& $\mathbf{6 0}$ & 5.6 & 5.4 & 5.1 & 4.5 \\
\hline \multirow{6}{*}{$\mathrm{CO}_{2}$} & $\mathbf{3 0}$ & 3.9 & 3.6 & 3.6 & 3.0 \\
& $\mathbf{4 0}$ & 6.7 & 6.5 & 6.4 & 6.3 \\
& $\mathbf{5 0}$ & 9.6 & 9.4 & 9.1 & 9.0 \\
& $\mathbf{6 0}$ & 15.2 & 13.9 & 14.1 & 13.2 \\
\hline
\end{tabular}

Figure 4 shows the results for the $P, D$ and $S$ coefficients at $30^{\circ} \mathrm{C}$ found in the distinct composites for the $\mathrm{CO}_{2}$ gas (differences observed are the largest for this gas). The former ones display a trend consisting in a decrease with the SBA-15 content. Both dependencies seem to point to presence in these membranes of confined PP chains inside the SBA-15 channels, which should be confirmed by other techniques. In principle, if the SBA-15 mesostructure would not be entirely filled, both magnitudes should undergo an increase due to the porous nature of the resultant materials. This growing behavior was previously described for membranes based on distinct mesoporous MCM-41 contents with either polysulfone processed by casting [31,32] or polyethylene processed by compression molding [33], where a rise in $D$ and $P$ was reported as mesoporous silica composition did. The enlargement in $D$ and 
$P$ was attributed to the presence of mesopores, in such a way that the penetrant gas molecules encountered less resistance to flow and to be translated through the, at least, partially empty channels. The tendencies shown by Figure 4 indicate that these mesoporous silica particles behave as fillers lacking in porosity. In contrast, the solubility (S) coefficient (Figure 4c) exhibits an increasing behavior as the amount of incorporated SBA-15 particles rises. This fact seems to indicate that there is an interaction between $\mathrm{CO}_{2}$ and mesoporous particles in the initial process of adsorption of the gas to the membrane.

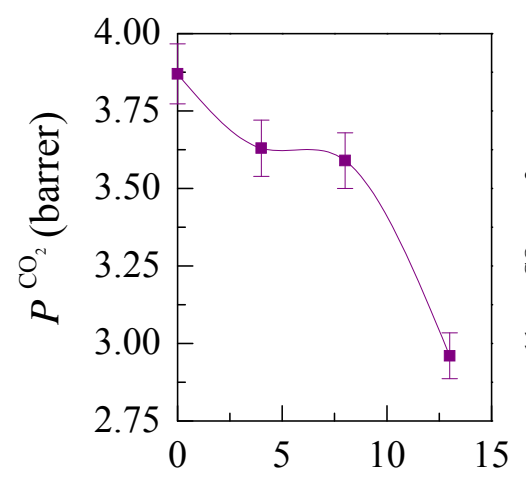

SBA-15 content (wt.\%)

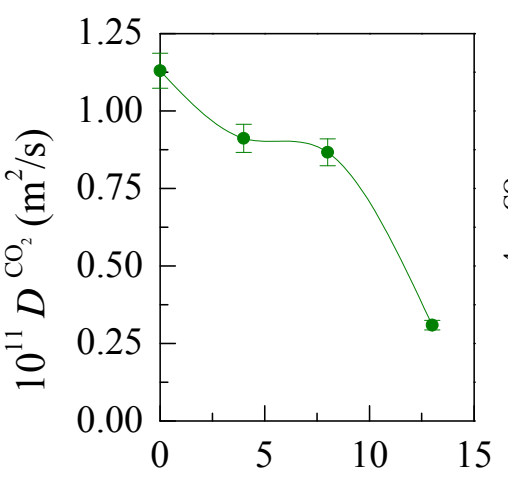

SBA-15 content (wt.\%)

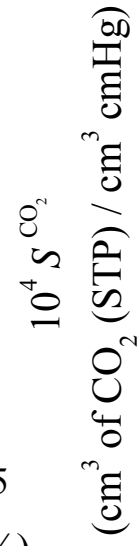

हृ

Figure 4. Dependence on SBA-15 content of the permeability, diffusion and solubility coefficients for $\mathrm{CO}_{2}$ gas in tests performed at $30^{\circ} \mathrm{C}$. Lines are just a guide to the eye.

\subsection{Crystalline characteristics and phase transitions}

Real-time variable-temperature SAXS experiments are here proposed to closely examine those eventual confinement effects, whose existence has been just indicated by the transport behavior to several gases. The use of this type of measurements was suggested at room temperature for some polymers [16-18], as mentioned along Introduction, although real-time variable-temperature profiles were not previously attempted for other polymeric-mesoporous silica based systems.

Before focusing the attention in the SAXS region, the effect of SBA-15 incorporation on the crystalline lattice of IPP will be analyzed. Figure 5 depicts the WAXD patterns at room temperature for the pristine IPP and different resulting hybrids, rapidly cooled from the melt. Only the monoclinic lattice is developed in this metallocene iPP matrix under these crystallization conditions [34]. Thus, the five main reflections, corresponding to the (110), (040), (130), (111), and $(-131,041)$ diffraction planes 
characteristic of the a iPP crystalline modification are observed, independently of presence of SBA-15 particles.

WAXD crystallinity, $f_{c}$ WAXD, of the IPP polymeric component can be assessed from these diffractograms after subtracting both the SBA-15 contribution and the amorphous polymeric component. The former is depicted in the inset of Figure 5 for the iPP-SBA13, where the pattern of the neat SBA-15 powder is shown together with the experimental IPP-SBA13 profile, before and after subtraction of its mesoporous content. It is clearly noticeable that the mesoporous silica particles are completely amorphous and its halo is overlapped in this range with the IPP profile. Concerning the amorphous polymeric component for each room-temperature profile represented in Figure 5, it should be commented that it is easily obtained from the diffractograms of the melt attained by variable-temperature WAXD (results not shown) with an appropriate shifting to account for the thermal expansion [22]. After those two subtractions, the total crystallinity values attained are detailed in Table 1. It is clearly deduced that crystallinity remains rather constant after incorporation of SBA-15, this value being practically inside the experimental error for all the composites.

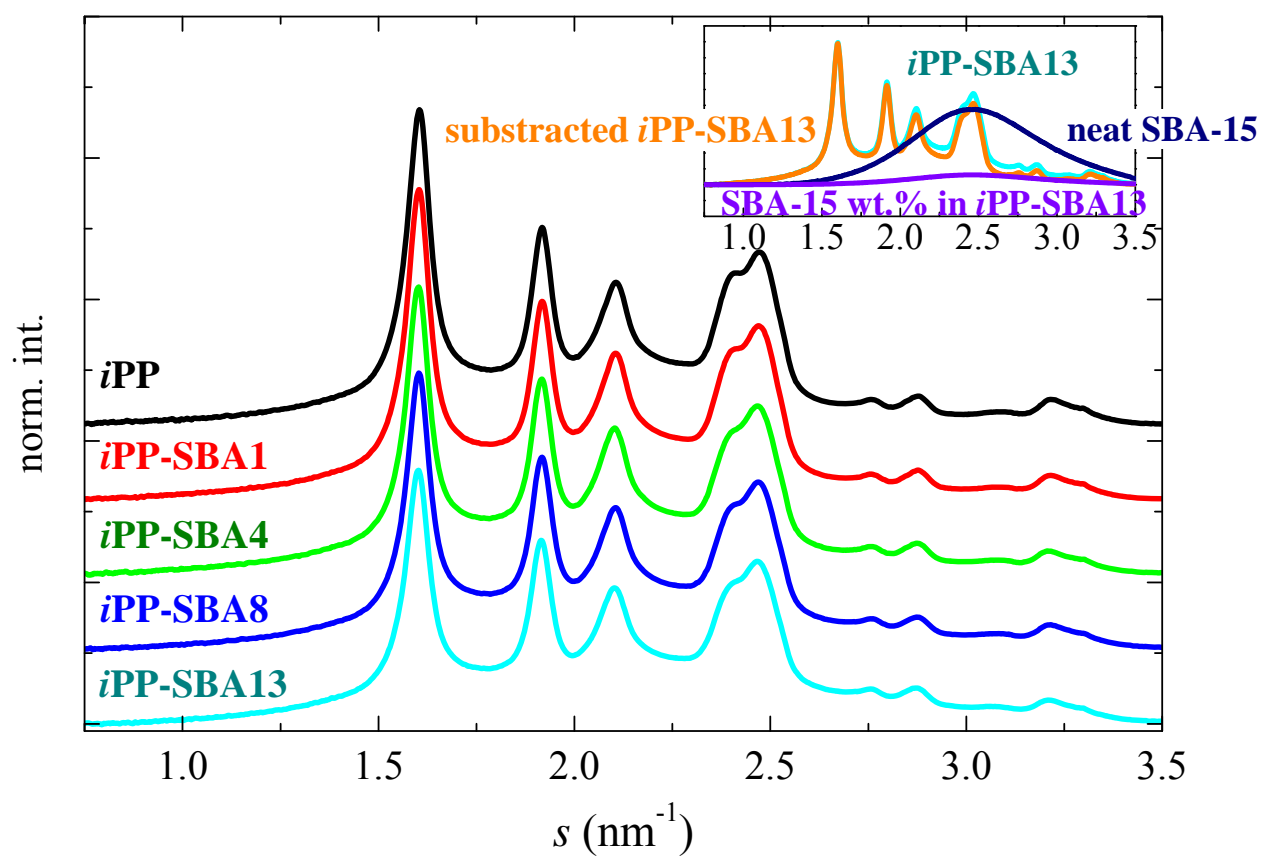

Figure 5. Synchrotron WAXD 1D diffractograms at room temperature for the different materials analyzed. Inset: subtraction of SBA-15 component in the iPP-SBA13, as an example.

Crystallinity values can be also deduced from DSC experiments. Figure 6 depicts the endotherms obtained during the first melting process for all the composites. Two different endothermic events are observed within this temperature interval: the main one occurring at around $142^{\circ} \mathrm{C}$ and other 
process taking place close to $100^{\circ} \mathrm{C}$. The former is ascribed to the melting of the regular iPP monoclinic crystallites. The endotherm at about $100^{\circ} \mathrm{C}$ is also related to polypropylene crystals but related to some of smaller sizes. Most probably, these crystals are those able to be developed within the nanometric SBA-15 channels that have contributed to the reduction of diffusion and permeability coefficients. These geometrical constraints (pore diameter of these channels is around $6 \mathrm{~nm}$ [19]) are responsible that the iPP macrochains pushed inside the SBA-15 mesoporosity by the shear forces during extrusion cannot grow as much as those iPP crystals located in the chains generated outside the SBA-15 pores. This feature was also found for hybrids based on HDPE and MCM-41, although melting of the confined polymer in those materials $[13,14]$ took place at around $80^{\circ} \mathrm{C}$ because of the smaller pore size in the MCM-41 channels. It was also observed at about $100^{\circ} \mathrm{C}$ in nanocomposites of polyethylene with higher molecular masses $[15,35]$ and SBA-15. This assumption will be corroborated by variable-temperature SAXS experiments, as aforementioned.

Figure 6 depicts that the total enthalpy involved in the primary endotherms seems to remain rather unchanged while the small process occurring at around $100{ }^{\circ} \mathrm{C}$ is strongly dependent on SBA-15 content in the final material. Crystallinity estimation has been performed after heat flow was normalized to the actual amount of polypropylene at each specimen. Values obtained, reported in Table 1, are rather analogous for the distinct composites. Moreover, there is a good agreement with those attained from the WAXD experiments, also shown in Table 1.

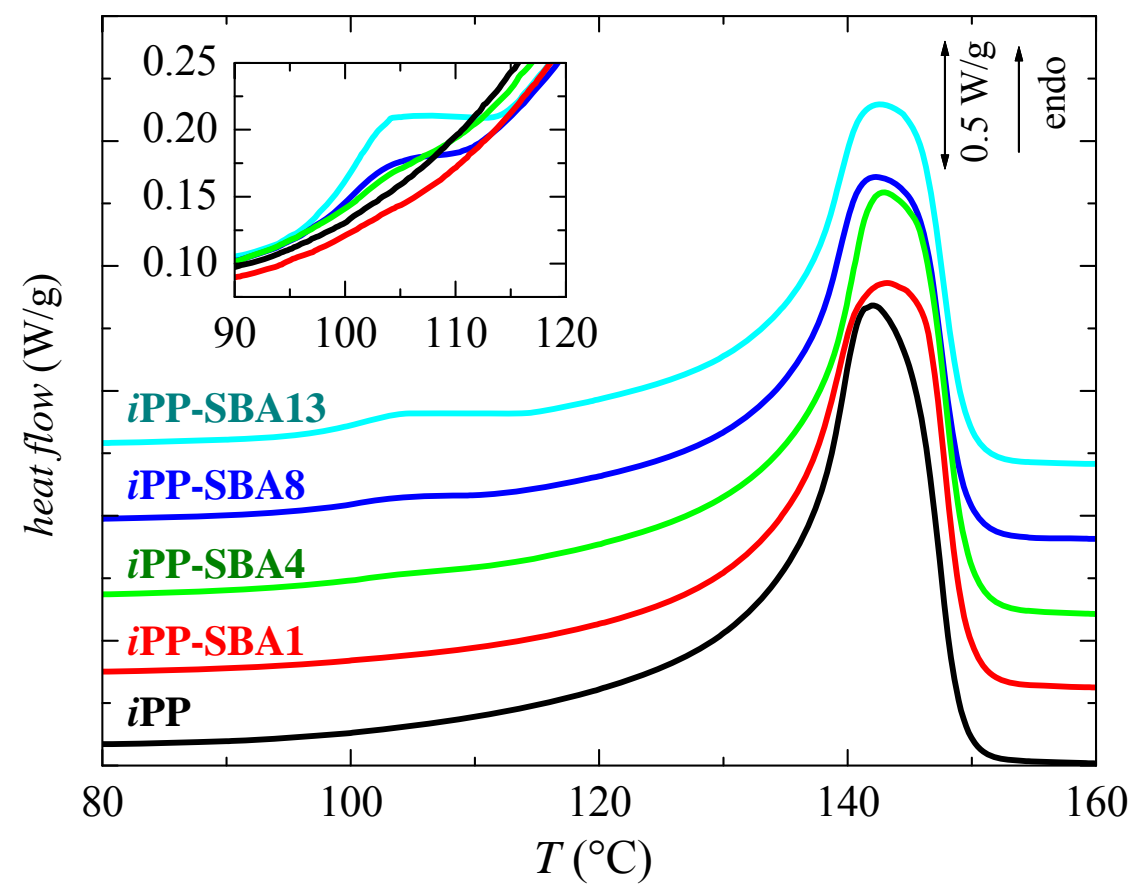

Figure 6. DSC curves for the first heating process in the iPP based materials with distinct SBA-15 content. Inset: amplification of the small endothermic event observed at $90-120^{\circ} \mathrm{C}$ 
Figure 7 shows the real-time variable temperature SAXS profiles for the SBA-15 particles and the composite iPP-SBA4. It is noticeable the ordered arrangement of this mesoporous silica, also observed by FESEM as depicted in Figure 1d for IPP-SBA13, associated with its hexagonal p6mm symmetry $[12,36]$ along the whole temperature interval analyzed. This ordering is characterized by existence of the reflections (100), (110), (200), (210) and (300) and it is maintained in IPP-SBA4 (and in the rest of the composites, as will be discussed below) along the whole temperature interval. Its intensity is, however, significantly reduced because now in the composite the SBA-15 particles are the minor component. This fact was also described at room temperature for PEI based composites with SBA-15 [18], where intensities of the SBA-15 diffraction peaks decreased with increasing PEI content.

Additionally to these diffractions ascribed to SBA-15, a broad peak is also evident for the IPPSBA4 in the region of low values of $s$. This is related to the change in the electron density existing in the iPP matrix due to its semicrystalline nature and its lamellar crystals, i.e., associated with its most probable long spacing.
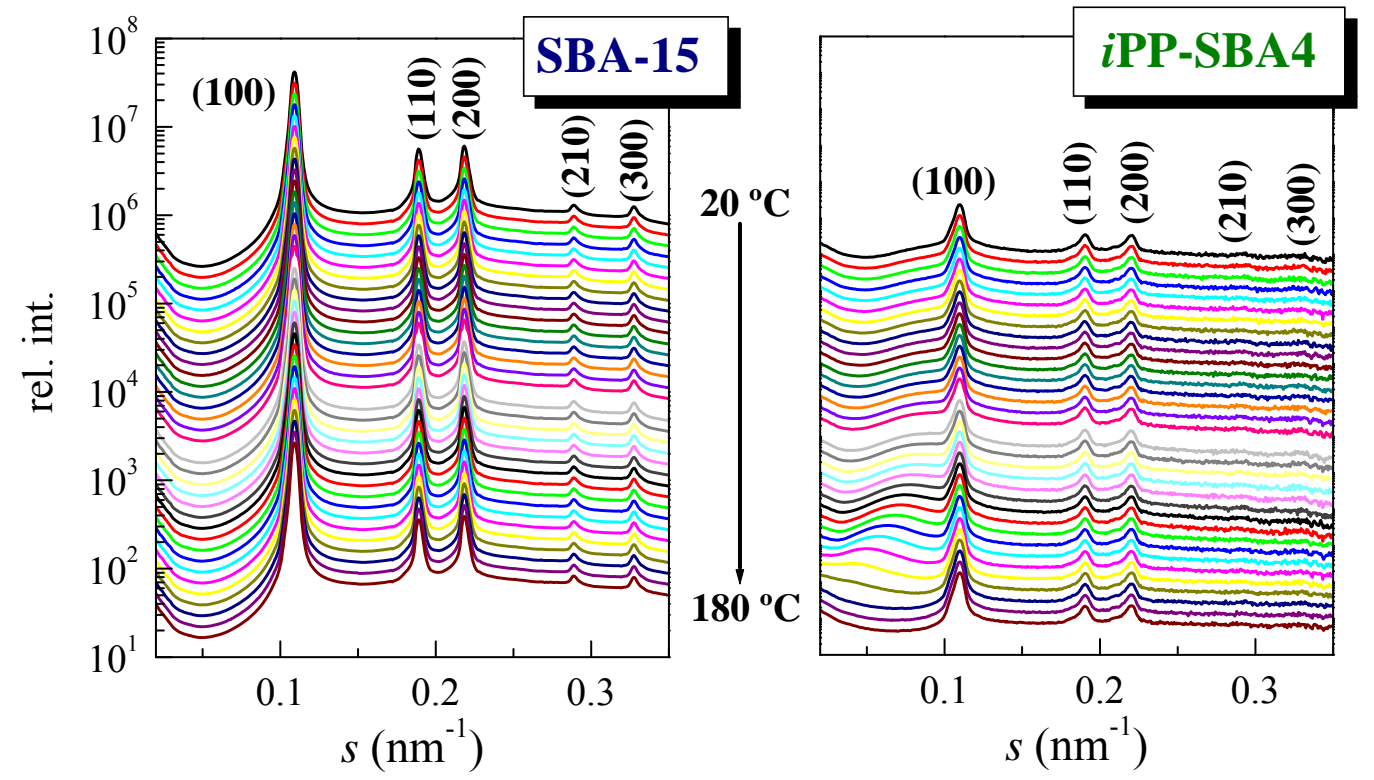

Figure 7. SAXS profiles obtained during the first melting process for SBA-15 (left) and for the IPP-SBA4 nanocomposite (right). Only one of every two frames is plotted for clarity.

This peak is lost once iPP melts since all the iPP chains become in a unique isotropic amorphous state. Figure 8a focuses the attention for the pristine iPP and different composites in this $s$ interval, up to $0.09 \mathrm{~nm}^{-1}$, where an overlapping with the more prominent first order in the hexagonal SBA-15 arrangement starts, to attain information about the most probable long spacing of IPP lamellar crystalline structure. 


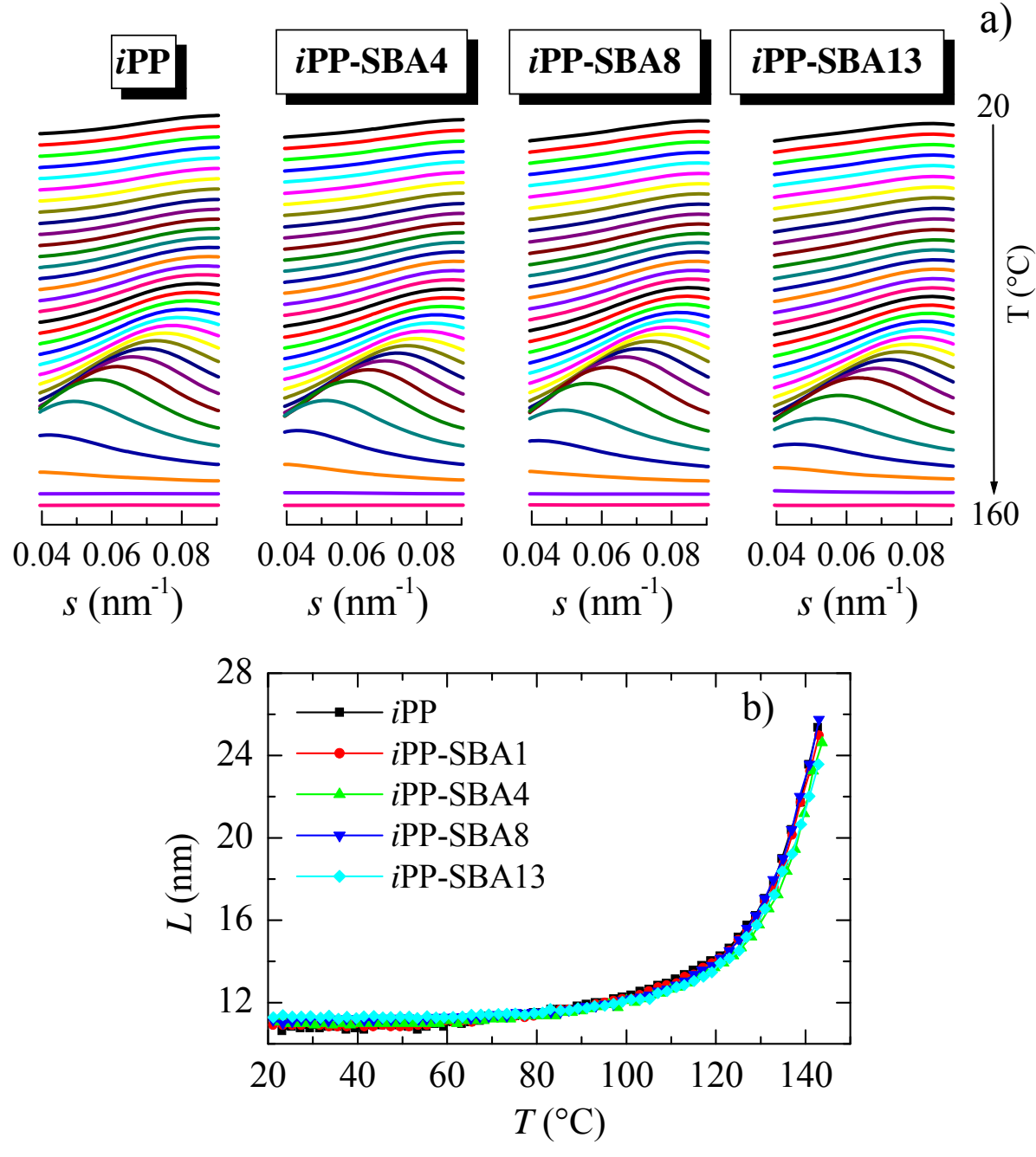

Figure 8. a) SAXS profiles during the first melting process in the $s$ interval ranging $0.04-0.09 \mathrm{~nm}^{-1}$ for the neat iPP and different IPP-SBA composites. Only one of every two frames is plotted for clarity. b) Temperature dependence of the most probable long spacing $(L)$ values for the several samples.

There are not many investigations dealing with polyolefins and mesoporous silicas and even less evaluating the most probable long spacing $[13,37]$. In those two articles, long spacing for HDPE increased when MCM-41 (either neat or decorated with undecenoic acid) content did. Values of long spacing at room temperature slightly increases (see Table 1 and Figure 8b) in these iPP based nanocomposites with SBA-15 content. Nevertheless, it must be taken into account that the uncertainty in its determination at low temperatures is extremely high because of superposition of the long spacing maximum with the first (100) hexagonal ordering of SBA-15 particles. Thus, a clear trend cannot be achieved since those differences are minimized on heating and values become analogous from $80^{\circ} \mathrm{C}$ as shown in Figure $8 \mathrm{~b}$. What is unambiguous is that an important shift of this peak to lower $s$ values (Figure 8a) together with and a considerable increase in the $L$ parameter (Figure $8 b$ ) is observed for all 
the samples as temperature rises, what is associated with the improvement of the IPP crystalline morphology and the thickening of the initially very defective iPP crystallites, which takes place through successive melting-recrystallization processes [38,39].

At higher $s$ values, a remarkable feature is observed within the interval from 0.095 to $0.13 \mathrm{~nm}^{-1}$, where only the first order of the hexagonal arrangement of the SBA-15 particles is involved. Figure 9a shows that neat IPP does not undergo any change, as expected, because variation of its long spacing occurs at a lower $s$ range, as just mentioned.

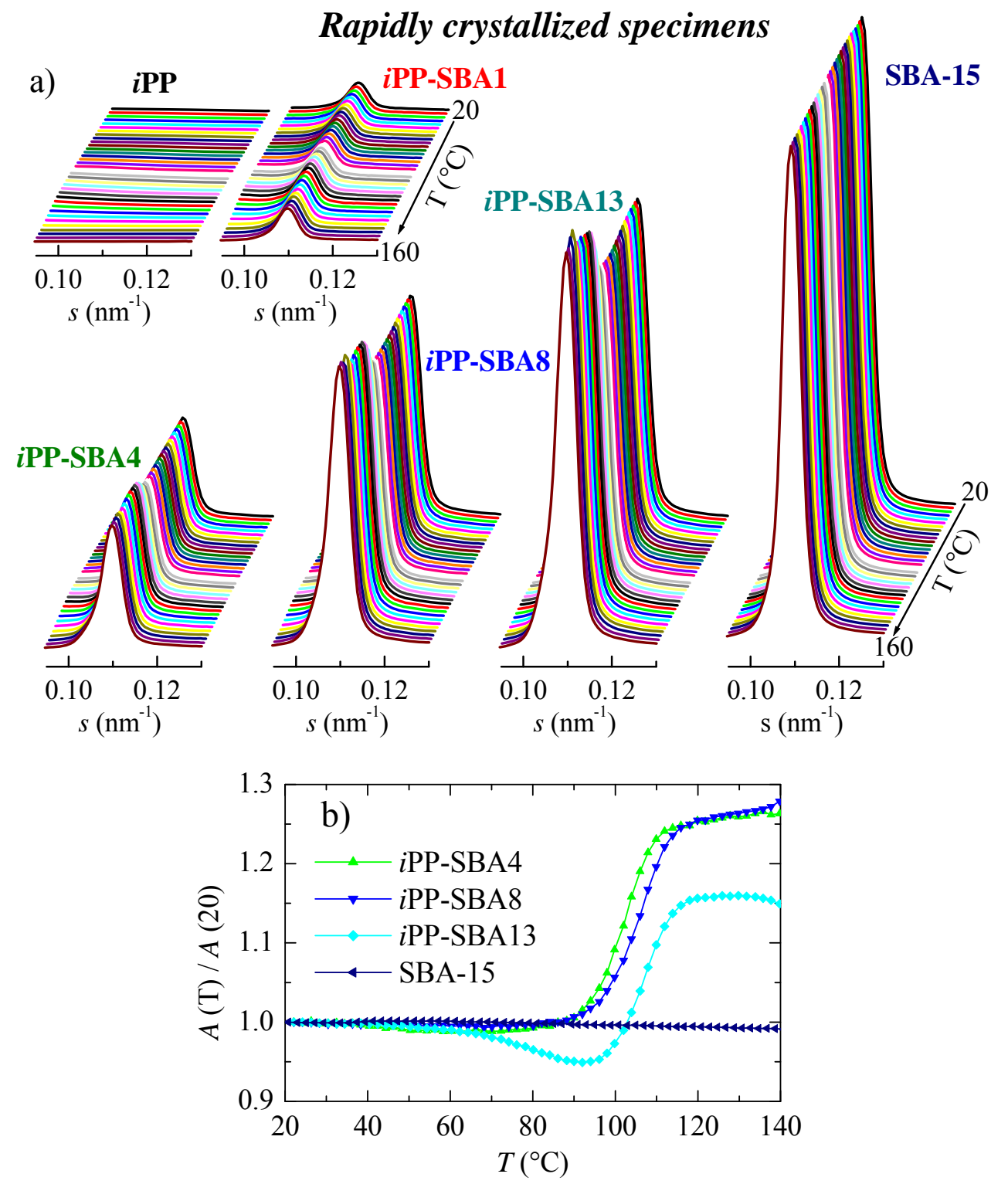

Figure 9. a) SAXS profiles during the first melting process for the distinct materials at the $s$ interval corresponding to the first order of SBA-15 hexagonal arrangement. Curves have been shifted for a better understanding, and the profiles for neat SBA-15 are divided by a factor of 7. b) Temperature dependence of the area for the main SBA-15 SAXS peak, normalized by its value at $20^{\circ} \mathrm{C}$, in the neat SBA-15 and different iPP nanocomposites during the melting experiments of Figure 7. 
Regarding the pristine SBA-15, it is clearly seen that the characteristics of its (100) reflection (position, intensity and width) are not altered in this temperature interval, from $20^{\circ} \mathrm{C}$ to $180^{\circ} \mathrm{C}$, at which the IPP melting takes place. On the contrary, all the different composites display an evident discontinuity in the intensity of the (100) SBA-15 diffraction. The magnitude of this step is clearly dependent on SBA15 content and it takes place for all of them at temperatures ranging from 95 to $120{ }^{\circ} \mathrm{C}$. This temperature interval is identical to that observed in the DSC endotherm of small intensity (see Figure 6) above commented. It was ascribed to the melting of those thin crystals confined in the space of SBA-15 channels that boosted the transport properties. This fact points out that the first order of the hexagonal SBA-15 arrangement is able of perceiving existence of iPP crystallites in the interior of its pores. These crystals possess an electronic density distinct than that in the amorphous regions of those confined macrochains. Variations in electronic density disappear when these small crystallites melt (at temperature lower than those IPP crystals from the outside chains because their lower size) and, then, the intensity of the (100) SBA-15 reflection becomes constant.

Figure 9b displays the variation in area of the (100) diffraction from the SBA-15 for distinct materials under study normalized by the initial value to make easier the comparison. The neat SBA-15 exhibits an almost constant normalized area in the whole temperature interval while a clear discontinuity is observed for the different composites. The presence of polymeric chains within the channel nanospaces indicates that these materials are nanocomposites, although the most of polymeric chains are outside the mesoporous silica since its content in the ultimate materials is not really high.

There was described in literature a relationship between intensity of the SBA-15 diffractions, in profiles only recorded at room temperature, and the content in mesoporous (nano)particles [18,40,41]. Changes were associated with modifications in the degree of pore filling and in the scattering contrast between the walls and the interior of the SBA-15 channels. Authors concluded that those variations in intensity were, consequently, an indication that the polymeric macromolecules were inside the SBA-15 pores. Similar interpretation was given for MCM-41 and KIT-6 materials [17,42]. Therefore, the existence of this discontinuity observed in Figure $9 a$ and $9 b$ is ascribed to the differences in the scattering contrast before and after the melting of the IPP crystallites confined inside the SBA-15 pores.

\subsection{Viscoelastic relaxations}

Crystalline aspects attempting to explain the trends in diffusion, permeability and solubility coefficients have been comprehensively evaluated. Nevertheless, knowledge of characteristics in the amorphous regions is also mandatory. Figure 10 shows the three existing viscoelastic relaxations exhibited in tan $\delta$ by the different IPP nanocomposites that occur in the temperature interval, from -100 to $150^{\circ} \mathrm{C}$. These three processes are labeled as $\alpha, \beta$ and $y$ in order of decreasing temperatures. The $\alpha$ 
relaxation is related to motions within the polymer crystalline phase, especially to defect diffusion [43]. The mechanism that takes place at around $0^{\circ} \mathrm{C}$ ( $\beta$ process) is ascribed to generalized motions of long chain segments that occur along the glass transition within the amorphous regions. The other relaxation process observed at temperatures lower than that related to cooperative motions is labeled as $Y$ and is associated with rotational motions of methyl groups from polypropylene. It does actually appear as a shoulder and not as a well-defined peak even in the iPP homopolymer (see Figure 10a).
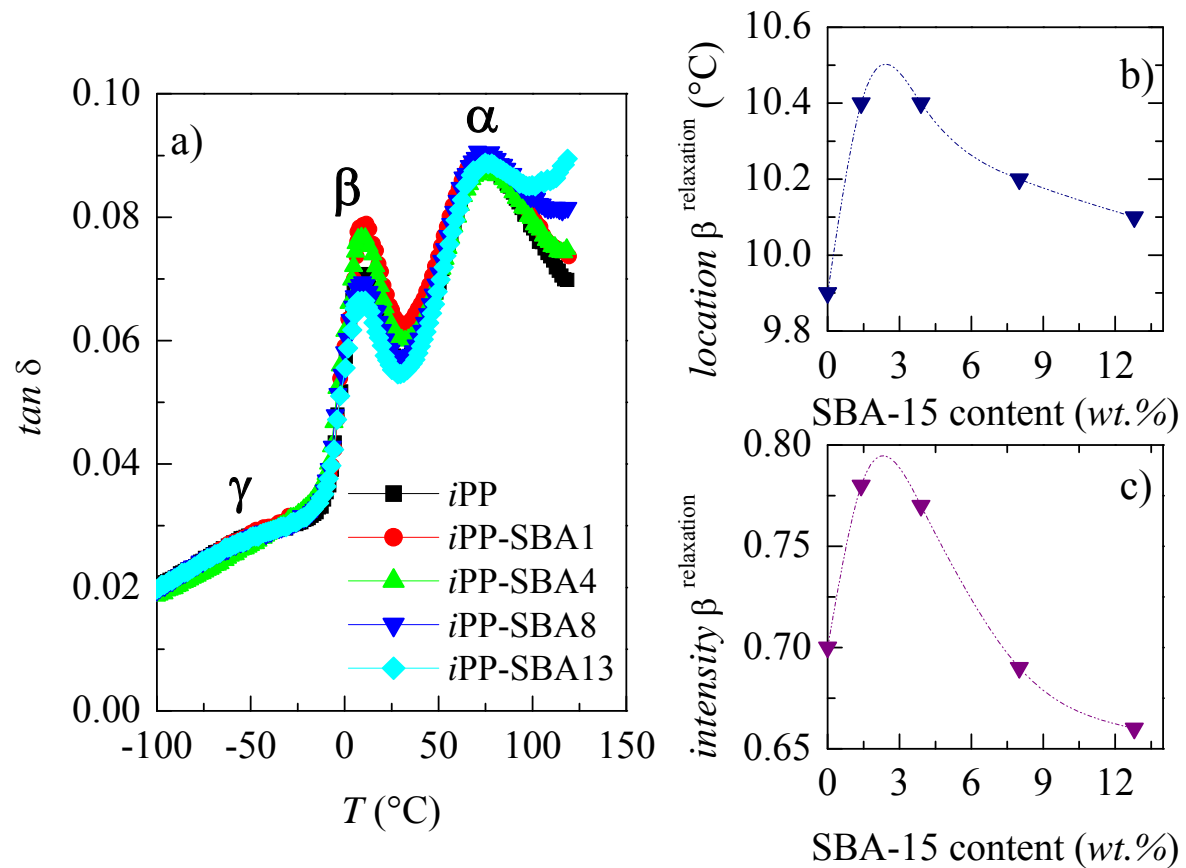

Figure 10. a) Temperature dependence of loss tangent (tan $\delta$ ) magnitude for the pristine iPP homopolymer and the different composites. b) Variation of the $\beta$ relaxation location and c) of its intensity with the SBA-15 wt. \% content.

Small variations are observed in the $\beta$ mechanism of $i \mathrm{PP}$ with the incorporation of SBA-15 particles (Figure $10 \mathrm{~b}$ ). Its location is shifted to slightly higher temperatures as mesoporous silica is introduced, this fact indicating that its presence boosted a hindrance in the amorphous regions of iPP. Its dependence is not straightforward with the SBA-15 content since appearance of a maximum is exhibited. There are IPP chains within the SBA-15 channels (as confirmed by the transport properties, DSC tests and SAXS evaluation) in such a way that, as SBA-15 amount is increased due to its relatively low overall contents, there are more iPP macrochains coming out from those channels that favor adhesion between silica and polymer and minimized its influence on the global mobility in the amorphous regions. Thus, its location decreases with content from the maximum value. Small 
differences are also evident in the intensity of this $\beta$ process. They might be ascribed to tiny changes in the details of the crystallites (see values in Table 1).

\subsection{Mechanical response}

The effect of presence of mesoporous SBA-15 particles on the mechanical behavior has been derived from stress-strain tests and indentation measurements. The main parameters obtained from the former are listed in Table 4 together with the storage modulus from DMTA experiments. Moreover, Figure 11 shows the results achieved from the indentation technique. A rather linear increase in the Young and storage moduli (as well as in the indentation modulus, $E_{i t}$ ) is observed as amount of SBA-15 is raised in the composite, as exhibited by Figure 12a, meaning that rigidity is increased. Variations in the different values are related to the distinct experimental conditions, the agreement in the several dependences being rather good. It should be said that results for iPP and PPP-SBA1 are very analogous (values in Table 4 and Figure 11) since there are not noticeable differences in features from either crystalline or amorphous regions, although SBA-15 dispersion was optimal as shown by FESEM image (Figure 1), but the amount incorporated is too small.
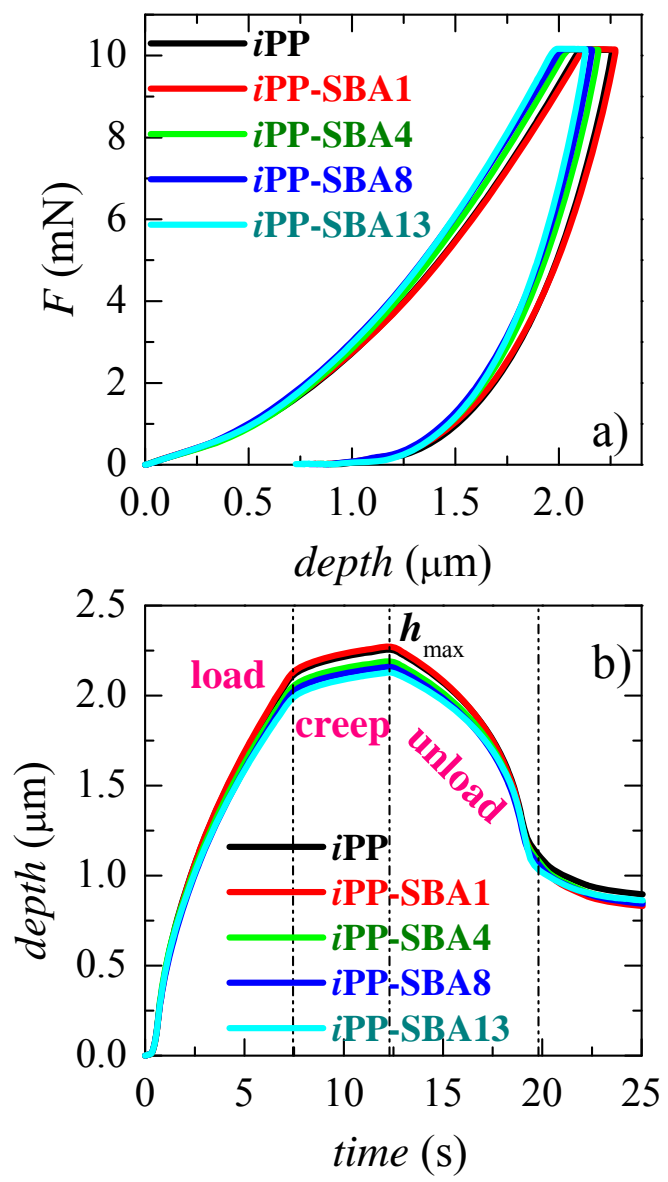

Figure 11. a) Load-maintenance-unload vs. depth curves; and b) Indentation depth dependence on time for the iPP homopolymer and the nanocomposites with different SBA-15 contents. 
Table 4: Mechanical parameters derived fro stress-strain tests at $25^{\circ} \mathrm{C}$ for the different rapidly crystallized samples: average Young's modulus $(E)$; yield stress $\left(\sigma_{Y}\right)$; yield deformation $\left(\varepsilon_{Y}\right)$; deformation at break ( $\left.\varepsilon_{\text {break }}\right)$. SBA-15 wt.\% content, crystallinity and DMTA storage modulus $\left(E^{\prime}\right)$ at $25^{\circ} \mathrm{C}$ and $3 \mathrm{~Hz}$ have been also listed.

\begin{tabular}{c|c|c|ccccc}
\hline sample & $\begin{array}{c}\text { SBA-15 } \\
\text { wt.\% by TGA }\end{array}$ & $f_{c}$ WAXD & $\begin{array}{c}E \\
(\mathrm{MPa})\end{array}$ & $\begin{array}{c}\sigma_{Y} \\
(\mathrm{MPa})\end{array}$ & $\begin{array}{c}\varepsilon_{Y} \\
(\%)\end{array}$ & $\begin{array}{c}\varepsilon_{\text {break }} \\
(\%)\end{array}$ & $\begin{array}{c}E^{\prime} \\
(\mathrm{MPa})\end{array}$ \\
\hline iPP & 0 & 0.60 & 1045 & 28.0 & 8.5 & 730 & 1545 \\
iPP-SBA1 & 1.4 & 0.60 & 1060 & 28.0 & 8.5 & 750 & 1565 \\
iPP-SBA4 & 3.9 & 0.59 & 1080 & 28.0 & 7.0 & 80 & 1690 \\
iPP-SBA8 & 8.0 & 0.59 & 1130 & 28.0 & 6.7 & 30 & 1830 \\
iPP-SBA13 & 12.8 & 0.58 & 1250 & 28.0 & 5.3 & 25 & 2040 \\
\hline
\end{tabular}
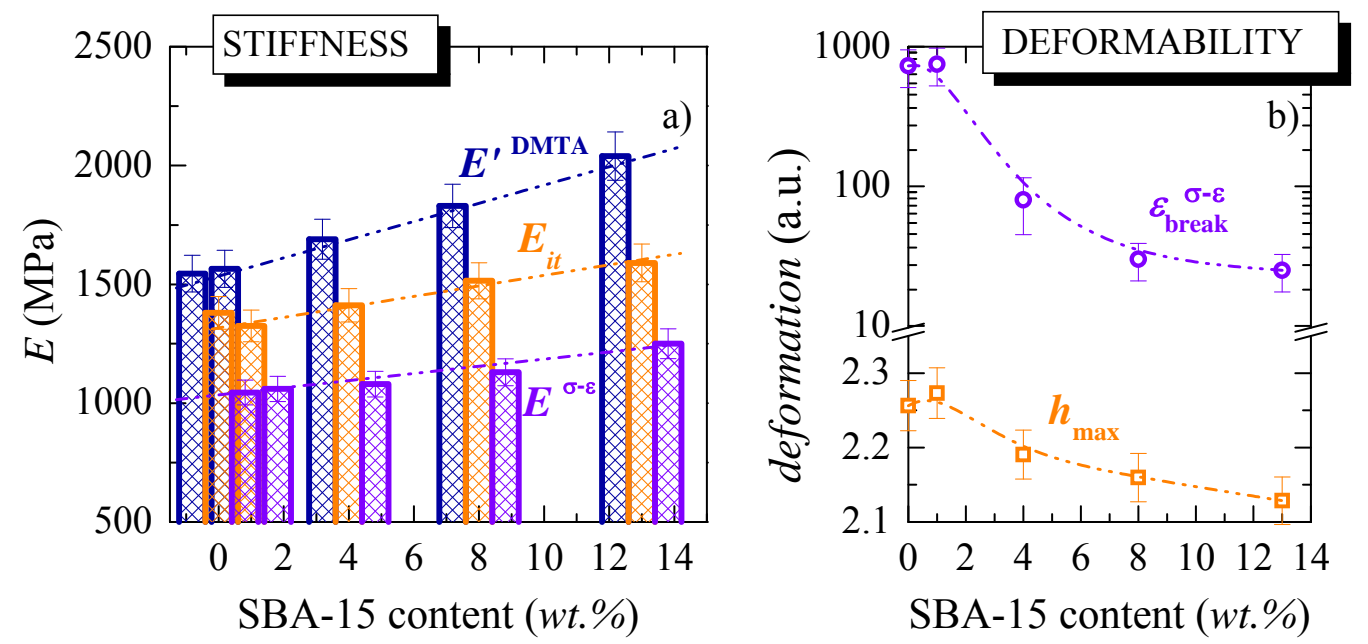

Figure 12. a) Values of modulus determined from DMTA, indentation and stress-strain measurements; and, b) deformation at break deduced from stress-strain tests and maximum depth at constant load $\left(h_{\max }\right)$ for the IPP homopolymer and nanocomposites with different SBA-15 contents.

Yield stress values are, however, independent of the presence of SBA-15 although the limit for the elastic regime becomes shorter and yield strain is, then, moved to lower deformation. The mentioned rise in stiffness significantly affects the resultant deformation at break and an important reduction in $\varepsilon_{\text {break }}$ is noticed with increasing mesoporous content (see data in Table 4 and Figure 12b). 
This smaller capability of being deformed is also deduced from Figure 11 during either loading or creep processes. In the former, indenter depth decreases at the end of that stage as SBA-15 increases. Moreover, $h_{\max }$, which is the depth reached when creep experiment at $10 \mathrm{mN}$ for $5 \mathrm{~s}$ finishes, is similarly reduced as mesoporous particles are raised in the materials, as displayed Figure 12b.

\section{Conclusions}

Nanocomposites based on iPP and different amounts (ranging from 1.4 to 12.8 wt.\%) of mesoporous SBA-15 silica have been prepared by melt extrusion. Influence of these particles on the gas transport properties and on their eventual confinement effects has been evaluated. FESEM pictures and SAXS results show that the well-defined hexagonal arrangement exhibited by the pristine SBA-15 is maintained in the particles embedded in the resultant nanocomposites.

Transport behavior appears rather similar for the iPP homopolymer, the iPP-SBA4 and the IPPSBA8 and show small variations in the composite IPP-SBA13 when $\mathrm{N}_{2}$ and $\mathrm{O}_{2}$ are studied. The situation changes for the $\mathrm{CO}_{2}$ gas and a much higher difference is noticed with content in mesoporous particles. Moreover, dependence on SBA-15 composition of the transport magnitudes proves that the mesostructure of silica is full, i.e., there is IPP within their nanometric channels, and these particles essentially act as fillers. Accordingly, a diminishment in permeability and diffusion coefficients is observed, related to an increase in tortuosity due to the inclusion of iPP chains that prevents the formation of a porous structure that would favor the penetration of the distinct gases.

Presence of those confined IPP chains in the SBA-15 pores is also deduced from the endothermic event that takes place close to $100{ }^{\circ} \mathrm{C}$, indicating the development of crystals of smaller size accommodated to the interior SBA-15 space. This assumption is supported by the strong dependence of the enthalpy involved on SBA-15 content in the final material.

Confinement is definitely confirmed by the noticeable discontinuity in the intensity of the (100) SBA-15 diffraction observed in the temperature range from 95 to $120^{\circ} \mathrm{C}$, which completely agrees with that noted in the small intensity DSC endotherm. The existence of this discontinuity is ascribed to differences in the scattering contrast before and after the melting of the PPP crystallites developed inside the SBA-15 pores. This variation of intensity is also dependent on SBA-15 content.

A rather linear increase is observed as amount of SBA-15 is raised in the composites for the different values of elastic moduli obtained from the several techniques. This feature points out the key role of SBA-15 particles as reinforcement. Simultaneously, deformation capability is reduced, which is also changing with SBA-15 content. 


\section{Acknowledgements}

This work was supported by the Agencia Estatal de Investigación (AEI, Spain) together with the European Regional Development Fund (FEDER, UE) [MAT2016-79869-C2-1-P]. Ms. R BarrancoGarcía also thanks her pre-doctoral funding [BES-2014-070972] associated with the MINECO [MAT2013-47972-C2-1-P] project. The synchrotron experiments were performed at beamline BL11NCD at ALBA Synchrotron Light Facility with the collaboration of ALBA staff. Authors are grateful for the funding received to perform these measurements.

\section{References}

\footnotetext{
1 O. Prieto, J.M. Pereña, R. Benavente, E. Pérez, M.L. Cerrada, Viscoelastic relaxation mechanisms of conventional polypropylene toughened by a plastomer, J. Polym. Sci. Polym. Phys. 41 (2003) 1878-1888.

2 C. Álvarez, A. Martínez-Gómez, E. Pérez, M.U. de la Orden, J.M. Urreaga, Thermal and morphological characteristics of polypropylene/smectic polyester blends, Polymer 48 (2007) 3137-3147.
}

3 A. Kubacka, M.L. Cerrada, C. Serrano, M. Fernández-García, M. Ferrer, M. Fernández-García, Light-driven novel properties of TiO2-modified Polypropylene-based Nanocomposite Films, J. Nanosci. Nanotech. 8 (2008) 3241-3246.

${ }^{4}$ M.L. Cerrada, C. Serrano, M. Sánchez-Chaves, M. Fernández-García, M.A. de Andrés, R.J. Riobóo, F. Fernández-Martín, A. Kubacka, M. Ferrer, M. Fernández-García, Biocidal Capability Optimization in Organic Inorganic Nanocomposites Based on Titania, Environ. Sci. Techn. 43 (2009) 1630-1634.

${ }^{5}$ M. Gupta, Y. Lin, T. Deans, E. Baer, A. Hiltner, D.A. Schiraldi, Structure and Gas Barrier Properties of Poly(propylene-graftmaleic anhydride)/Phosphate Glass Composites Prepared by Microlayer Coextrusion, Macromolecules 43 (2010) 42304239.

6 Tiphaine Messin, Nadège Follain, Alain Guinault, Guillaume Miquelard-Garnier, Cyrille Sollogoub, Nicolas Delpouve, Valérie Gaucher, Stéphane Marais, Confinement effect in PC/MXD6 multilayer films: Impact of the microlayered structure on water and gas barrier properties. J. Membr. Sci. 525 (2017) 135-145.

7 X. Zhu, C. Melian, Q. Dou, K. Peter, D.E. Demco, M. Möller, D.V. Anokhin, J.-M. Le Meins, D.A. Ivanov, Morphology of Injection-Molded Isotactic Polypropylene/Silica Composites Prepared via in-Situ Sol-Gel Technology, Macromolecules 43 (2010) 6067-6074.

8 J. Arranz-Andrés, E. Pérez, M.L. Cerrada, Nanocomposites based on Isotactic Polypropylene-Copper Nanoparticles as Electromagnetic Shields, Sci. Adv. Mater. 5 (2013) 1524-1532.

9 J. Arranz-Andrés, E. Pérez, M.L. Cerrada, Lightweight Nanocomposites based on Polypropylene and Aluminum Nanoparticles and their Shielding Capability to lonizing Radiation, IEEE T. Nanotechnol. 13 (2014) 502-509.

10 G. Bounos, K.S. Andrikopoulos, H. Moschopoulou, G.Ch. Lainioti, D. Roilo, R. Checchetto, T. loannides, J.K. Kallitsis, G.A. Voyiatzis. Enhancing water vapor permeability in mixed matrix polypropylene membranes through carbon nanotubes dispersion, J. Membr. Sci. 524 (2017) 576-584.

11 J.S. Beck, J.C. Vartuli, W.J. Roth, M.E. Leonowicz, C.T. Kresge, K.D. Schmitt, C.T.-W. Chu, D.H. Olson, E.W. Sheppard, S.B. McCullen, J.B. Higgins, J.L. Schlenkert, A New Family of Mesoporous Molecular Sieves Prepared with Liquid Crystal Templates, J. Am. Chem. Soc. 114 (1992) 10834-10843.

12 D.Y. Zhao, J.L. Feng, Q.S. Huo, N. Melosh, G.H. Fredrickson, B.F. Chmelka, G.D. Stucky, Triblock Copolymer Syntheses of Mesoporous Silica with Periodic 50 to 300 Angstrom Pores, Science 279 (1998) 548-552.

13 M.L. Cerrada, E. Pérez, J.P. Lourenço, A. Bento, M.R. Ribeiro, Decorated MCM-41/polyethylene hybrids: Crystalline Details and Viscoelastic Behavior, Polymer 54 (2013) 2611-2620.

${ }_{14}$ M.L. Cerrada, A. Bento, E. Pérez, V. Lorenzo, J.P. Lourenço, M.R. Ribeiro, Hybrid Materials Based on Polyethylene and MCM-41 Particles Functionalized with Silanes: Catalytic Aspects of In Situ Polymerization, Crystalline Features and Mechanical Properties, Micropor. Mesopor. Mater. 232 (2016) 86-96.

15 A.E. Ferreira, M.L. Cerrada, E. Pérez, V. Lorenzo, H. Cramail, J.P. Lourenço, M.R. Ribeiro, UHMWPE/SBA-15 nanocomposites synthesized by in situ polymerization, Micropor. Mesopor. Mater. 232 (2016) 13-25.

16 A. de Sousa, E. Martins Barros de Sousa, R.G. de Sousa, Synthesis and Characterization of Poly(Nisopropylacrylamide)/SBA-15 Silica Nanocomposites, J. Nanosci. Nanotechn. 15 (2015) 9438-9448.

17 X. Xu, Ch. Song, J.M. Andrésen, B.G. Miller, A.W. Scaroni, Preparation and characterization of novel $\mathrm{CO}_{2}$ "molecular basket" adsorbents based on polymer-modified mesoporous molecular sieve MCM-41, Micropor. Mesopor. Mater. 62 (2003) 29-45. 
${ }^{18}$ X. Wang, X. Ma, Ch. Song, D.R. Locke, S. Siefert, R.E. Winans, J. Möllmer, M. Lange, A. Möller, R. Gläser, Molecular basket sorbents polyethylenimine-SBA-15 for $\mathrm{CO} 2$ capture from flue gas: Characterization and sorption properties, Micropor. Mesopor. Mater. 169 (2013) 103-111.

${ }^{19}$ A. Deryło-Marczewska, M. Zienkiewicz-Strzałka, K. Skrzypczyńska, A. Światkowski, K. Kuśmierek, Evaluation of the SBA15 materials ability to accumulation of 4-chlorophenol on carbon paste electrode, Adsorption 22 (2016) 801-812.

${ }^{20}$ E.B. Bond, J.E. Spruiell, J.S. Lin, A WAXD/SAXS/DSC study on the melting behavior of Ziegler-Natta and metallocene catalyzed isotactic polypropylene, J. Polym. Sci. Part B: Polym. Phys. 37 (1999) 3050-3064.

${ }^{21}$ R. Krache, R. Benavente, J.M. Lopez-Majada, J.M. Pereña, M.L. Cerrada, E. Perez, Competition between alpha, beta and gamma polymorphs in a beta-nucleated metallocene isotactic polypropylene, Macromolecules 40 (2007) 6871-6878.

${ }_{22}$ E. Pérez, M.L. Cerrada, R. Benavente, J.M. Gómez-Elvira, Enhancing the formation of the new trigonal polymorph in isotactic propene-1-pentene copolymers: determination of the X-ray crystallinity, Macromol. Res. 19 (2011) 1179-1185.

${ }^{23}$ K. Kageyama, J. Tamazawa, T. Aida, Extrusion Polymerization: Catalyzed Synthesis Of Crystalline Linear Polyethylene Nanofibers Within A Mesoporous Silica, Science 285 (1999) 2113-2115.

${ }^{24}$ X. Dong, L. Wang, W. Wang, H. Yu, J. Wang, T. Chen, Z. Zhao, Preparation of nano-polyethylene fibers and floccules using MCM-41-supported metallocene catalytic system under atmospheric pressure, Eur. Polym. J. 41 (2005) 797-803.

25 J.G. Wijmans, R.W. Baker, The solution-diffusion model: a review, J. Membr. Sci., 107 (1995) 1-21.

${ }^{26}$ S.W. Rutherford, D.D. Do, Review of time lag permeation technique as a method for characterisation of porous media and membranes, Adsorpt.-J. Int. Adsorpt. Soc., 3 (1997) 283-312.

${ }^{27}$ A.S. Michaels, H.J. Bixler, Flow of gases through polyethylene, J. Polym. Sci. 50 (1961) 413-439.

${ }^{28}$ A.S. Michaels, R.B. Parker Jr., Sorption and flow of gases in polyethylene, J. Polym.Sci. 41 (1959) 53-71.

${ }^{29}$ M.F. Laguna, M.L. Cerrada, R. Benavente, E. Pérez. Effect of the comonomer content on the permeation behavior in polyolefin films synthesized with metallocene catalysts. J. Membr. Sci. 212 (2003) 167-176.

30 G. Choudalakis, A. D. Gotsis, Permeability of polymer/clay nanocomposites: A review, Eur. Polym. J. 45 (2009) 967-984.

${ }_{31}$ B.D. Reid, F.A. Ruiz-Trevino, I.H. Musselman, K.J. Balkus, J.P. Ferraris, Gas permeability properties of polysulfone membranes containing the mesoporous molecular sieve MCM-41, Chem. Mater. 13 (2001) 2366-2373.

$32 \mathrm{~S}$. Kim, E. Marand, High permeability nano-composite membranes based on mesoporous MCM-41nanoparticles in a polysulfone matrix, Micropor. Mesopor. Mat. 114 (2008) 129-136.

${ }_{33}$ A. Bento, J. P. Lourenço, A. Fernandes, M. R. Ribeiro, J. Arranz-Andrés, V. Lorenzo, M. L. Cerrada. Gas permeability properties of decorated MCM 41/polyethylene hybrids prepared by in situ polymerization. J. Membr. Sci. 415-416 (2012) 702-711.

${ }^{34}$ H. Palza, J. M. López-Majada, R. Quijada, J. M. Pereña, R. Benavente, E. Pérez, M. L. Cerrada. Comonomer Length Influence on the Structure and Mechanical Response of Metallocenic Polypropylenic Materials. Macromol. Chem. Phys. 209 (2008) 2259-2267.

${ }_{35}$ A.E. Ferreira, M.L. Cerrada, E. Pérez, V. Lorenzo, H. Cramail, J.P. Lourenço, R. Quijada, M.R. Ribeiro, Hafnocene catalyst for polyethylene and its nanocomposites with SBA-15 by in situ polymerization: immobilization approaches, catalytic behavior and properties evaluation, Eur. Polym. J. 85 (2016) 298-312.

36 D.Y. Zhao, Q.S. Huo, J.L. Feng, B.F. Chmelka, G.D. Stucky, Nonionic Triblock and Star Diblock Copolymer and Oligomeric Surfactant Syntheses of Highly Ordered, Hydrothermally Stable, Mesoporous Silica Structures, J. Am. Chem. Soc. 120 (1998) 6024-6036.

${ }^{37}$ M.L. Cerrada, E. Pérez, J.P. Lourenço, J.M. Campos, M.R. Ribeiro, Hybrid HDPE/MCM-41 Nanocomposites: Crystalline Structure and Viscoelastic Behaviour, Micropor. Mesopor. Mater. 130 (2010) 215-223.

38 J.M. López Majada, H. Palza, J.L. Guevara, R. Quijada, M.C. Martínez, R. Benavente, J.M. Pereña, E. Pérez, M.L. Cerrada, Metallocenic Copolymers of Propene and 1 Hexene: Influence of Comonomer Content and Thermal History on the Structure and Mechanical Properties, J. Polym. Sci. Polym. Phys. 44 (2006) 1253-1267.

${ }^{39}$ C. Serrano, M.L. Cerrada, M. Fernández-García, J. Ressia, E.M. Vallés, Rheological and Structural Details of Biocidal iPPTiO2 Nanocomposites, Eur. Polym. J. 48 (2012) 586-596.

$40 \mathrm{~J}$. Sauer, F. Marlow, F. Schüth, Simulation of powder diffraction patterns of modified ordered mesoporous materials, Phys. Chem. Chem. Phys. 3 (2001) 5579-5584.

${ }_{41}$ W. Hammond, E. Prouzet, S.D. Mahanti, T.J. Pinnavaia, Structure factor for the periodic walls of mesoporous MCM-41 molecular sieves, Micropor. Mesopor. Mat. 27 (1999) 19-25.

42 W.J. Son, J.S. Choi, W.S. Ahn, Adsorptive removal of carbon dioxide using polyethyleneimine-loaded mesoporous silica materials, Micropor. Mesopor. Mater. 113 (2008) 31-40.

${ }^{43}$ C. Jourdan, J.Y. Cavaille, J. Perez, Mechanical relaxations in polypropylene - a new experimental and theoretical approach, J. Polym. Sci. Part B Polym. Phys. 27 (1989) 2361-2384. 